\title{
Endoscopic ultrasound-guided coil embolization and thrombin injection of a bleeding gastroduodenal artery pseudoaneurysm
}

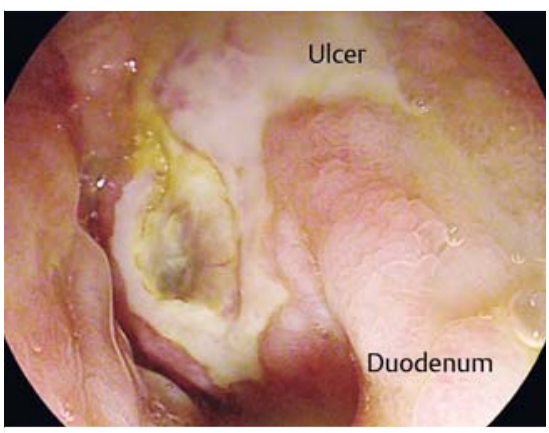

Fig. 1 Side-viewing endoscopy showed a pulsatile bulge with a large overlying ulcer.

A 50-year-old man had an episode of alcohol-induced acute pancreatitis 1 month before presenting with melena, which required six units of transfused blood for hemodynamic stabilization. After hemodynamic resuscitation, the patient underwent upper gastrointestinal endoscopy. Upper endoscopy showed a bulge with overlying ulceration in the second part of the duodenum. Side-viewing endoscopy showed a pulsatile bulge with a large overlying ulcer ( $\triangleright$ Fig.1). Abdominal ultrasound showed a pseudoaneurysm of size $3.8 \times 5.6 \mathrm{~cm}$ arising from the gastroduodenal artery (GDA). Abdominal computed tomography with angiography showed a saccular pseudoaneurysm of size $4 \times 6 \mathrm{~cm}$ in relation to the GDA ( $\mathbf{F i g} \cdot \mathbf{2})$. Endoscopic ultrasound (EUS) from the duodenal bulb showed a pseudoaneurysm of size $4.1 \times$ $5.8 \mathrm{~cm}$ arising from the GDA ( Fig. 3 a). Radiological or EUS-guided interventions were considered. The patient selected the option of EUS-guided coil embolization ( $\vee$ Video 1$)$.

Under EUS and fluoroscopy guidance, five $10-\mathrm{mm}$ coils were placed within the pseudoaneurysm through a 19-gauge EUS needle ( $\triangleright$ Fig. $\mathbf{3 b}$ ). After coil embolization, contrast injection into the pseudoaneurysm showed partial filling of the

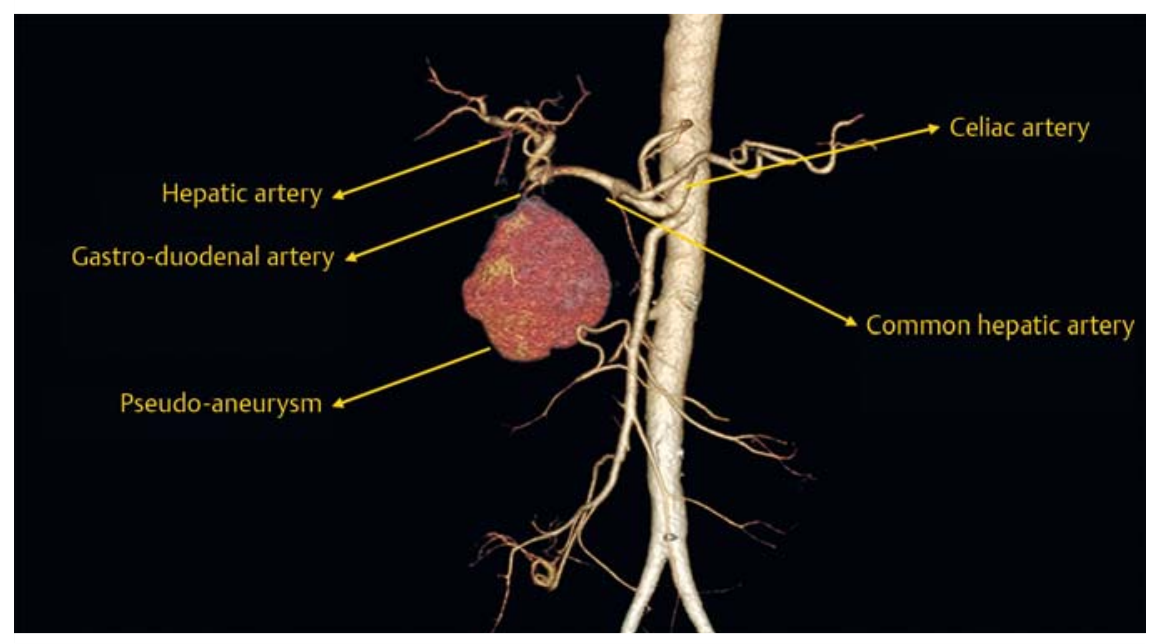

- Fig. 2 Abdominal computed tomography with angiography showed a saccular pseudoaneurysm of size $4 \times 6 \mathrm{~cm}$ in relation to the gastroduodenal artery.
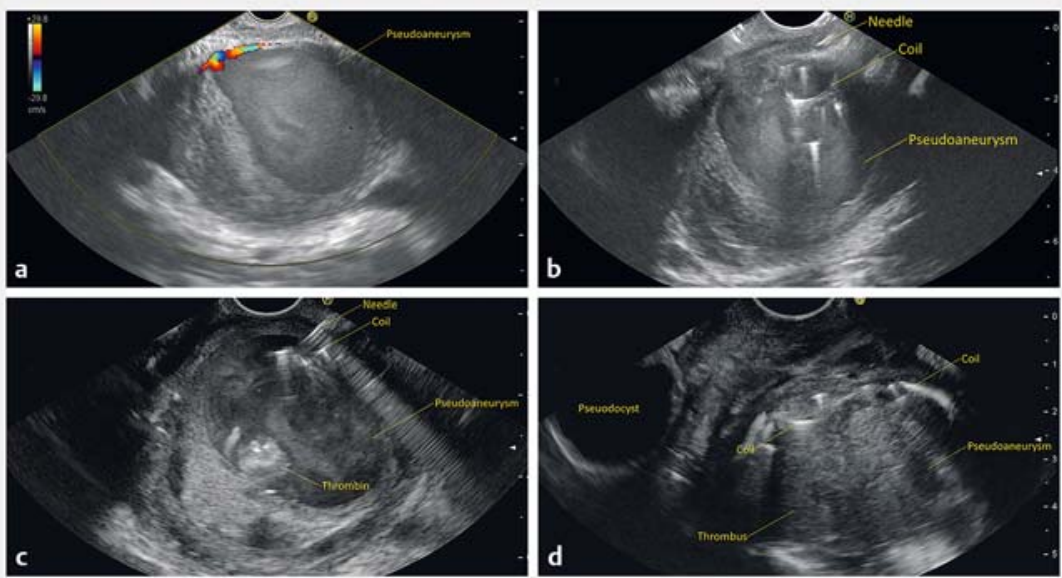

- Fig. 3 Endoscopic ultrasound (EUS) images. a EUS from the duodenal bulb showed a pseudoaneurysm of size $4.1 \times 5.8 \mathrm{~cm}$ arising from the gastroduodenal artery. $\mathbf{b}$ Under EUS and fluoroscopy guidance, five 10 -mm coils were placed within the pseudoaneurysm through a 19-gauge EUS needle. c $1 \mathrm{~mL}$ of human thrombin ( $500 \mathrm{IU}$ ) was injected into the pseudoaneurysm through a 22-gauge needle. $\mathbf{d}$ Complete obliteration of the pseudoaneurysm with hyperechoic thrombus with no blood flow.

pseudoaneurysm. Follow-up EUS 1 day after coil embolization showed high flow in the pseudoaneurysm. Around $30 \%$ of the pseudoaneurysm was obliterated. On the third day, $6 \mathrm{~mL}$ of human throm- bin $(3000 \mathrm{IU})$ was injected in six boluses of $500 \mathrm{IU}$ each ( $\boldsymbol{F i g} \cdot \mathbf{3 c}$ ). After thrombin injection, high velocity flow was confined to the neck and periphery of the pseudoaneurysm. A further $2 \mathrm{~mL}$ of 


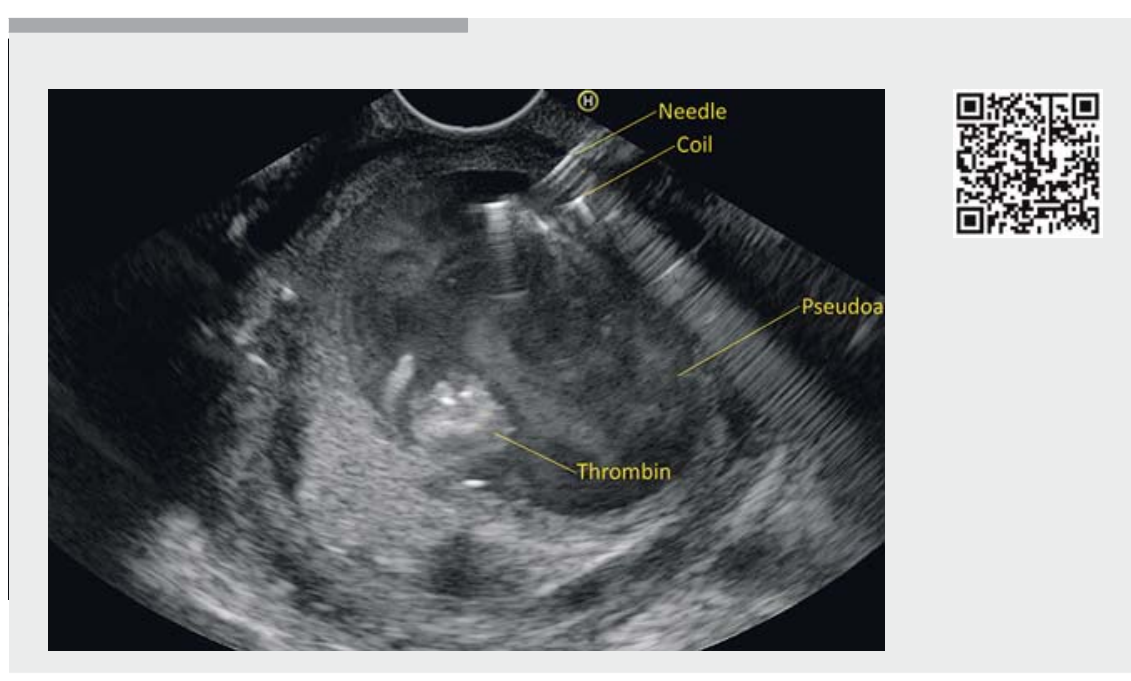

Video 1 Endoscopic ultrasound-guided coil embolization and thrombin injection of a bleeding gastroduodenal artery pseudoaneurysm.

thrombin was injected. Immediately after thrombin injection, color Doppler EUS showed complete obliteration of the pseudoaneurysm ( $\mathbf{F i g} \cdot \mathbf{3} \mathbf{d}$ ). Repeat EUS 2 weeks later showed a completely obliterated pseudoaneurysm with no flow.

This case shows the practical problems of EUS-guided coil embolization of pseudoaneurysms. Further studies are required regarding the best modality or combination of modalities of EUS-guided treatment of pseudoaneurysms with coils, glue or thrombin.

Endoscopy_UCTN_Code_TTT_1AO_2AD
Acknowledgment

The authors thank Pran Prakash for assistance with the graphics.

\section{Competing interests}

None

The authors

Malay Sharma ${ }^{1}$, Piyush Somani ${ }^{1}$, Tagore Sunkara ${ }^{2}$, Ritesh Prajapati ${ }^{1}$, Rahul Talele ${ }^{1}$

1 Department of Gastroenterology, Jaswant Rai Speciality Hospital, Meerut, India

2 Department of Gastroenterology and Hepatology, The Brooklyn Hospital Center, Clinical Affliate of the Mount Sinai Hospital, Brooklyn, New York, United States
Corresponding author

\section{Malay Sharma, MD, DM}

Department of Gastroenterology, Jaswant Rai Speciality Hospital, Saket, Meerut, PIN-250 001, Uttar Pradesh, India

Fax: +91-121-2657154

sharmamalay@hotmail.com

\section{Bibliography}

DOI https://doi.org/10.1055/a-0790-8134

Published online: 11.12.2018

Endoscopy 2019; 51: E36-E37

(c) Georg Thieme Verlag KG

Stuttgart · New York

ISSN 0013-726X

\section{ENDOSCOPY E-VIDEOS}

https:/|eref.thieme.de/e-videos

Endoscopy E-Videos is a free access online section, reporting 售: on interesting cases and new techniques in gastroenterological endoscopy. All papers include a high quality video and all contributions are freely accessible online.

This section has its own submission website at

https://mc.manuscriptcentral.com/e-videos 